\title{
River Flow Modelling for Sustainable Operation of Hydroelectric Power Plant in the Taludaa-Gorontalo Watershed
}

\author{
Sardi Salim ${ }^{*}$, Muchlis Polin ${ }^{2}$ \\ ${ }^{1}$ Electrical Engineering Department, Universitas Negeri Gorontalo, Gorontalo, Indonesia, ${ }^{2}$ Information Systems \\ Department, Universitas Negeri Gorontalo, Gorontalo, Indonesia
}

Received: 2021-04-27

Accepted: 2021-11-29

Keywords:

Modelling;

hydrology;

discharge;

watershed;

electric power

Correspondent email: sardi@ung.ac.id

\begin{abstract}
River flow discharge is generally measured by multiplying the cross-sectional river area at the measurement point with the flow velocity. However, this approach cannot be used for planning needs which involves knowing the changes in discharge values at all times, which are directly affected by the variations in weather conditions and catchment area systems. This is necessary because planning errors usually lead to unsustainable and interrupted operations. It is possible to determine the changes in the river discharge values using the rainfall-runoff modelling technique through the hydrograph output of the model. Therefore, this study used hydrological modelling techniques to obtain a watershed's spatial and temporal river flow discharge. This involved using parameters such as watershed area, curve number representing land use and soil type, time lag as the delay between maximum rainfall and the occurrence of peak discharge, and the initial abstraction that considers all the losses before the runoff occurred. Moreover, rainfall data were obtained from an ARR station installed around the watershed area, while water level data were retrieved through an AWLR station installed in the river at the debit measurement point. The model was analyzed using HEC-HMS software, while the dependable discharge for power plants was analyzed using the flow duration curve method. The results showed that the rainfall-runoff hydrological modelling technique applied to the Taludaa-Gorontalo sub-watershed could ensure the continuous and sustainable operation of the hydroelectric power plant.
\end{abstract}

@2021 by the authors. Licensee Indonesian Journal of Geography, Indonesia.

his article is an open access article distributed under the terms and conditions of the Creative Commons

Attribution(CC BY NC) licensehttps://creativecommons.org/licenses/by-nc/4.0/.

\section{Introduction}

One of the major problems often encountered in hydropower planning is the mismatch between the value of the actual river discharge and the potential discharge needed every time to operate a plant (Tsai et al., 2016). Several electric power project planners usually rely on river flow studies by measuring the cross-sectional area of the river $(A)$ and water flow velocity $(V)$ to determine the river discharge based on $Q=A \times V \mathrm{~m}^{3} / \mathrm{sec}$. However, this method can only provide the discharge value at the time of measurement without any information on the climate change in the catchment area overtime or the river discharge value for one year. This limits the ability of the hydropower plant to operate at full capacity even though it does not rain (Amos et al., 2016). Meanwhile, the power plant components can be damaged during heavy rainfall, thereby allowing water to exceed the capacity of the river weir or water channel for a longer period. This means there is a need to know the dependable discharge trends to determine the potential of the river to be used in turning a power generator turbine constantly (Samora et al., 2016).

Therefore, a method is needed to assess the ability of a river flow to guarantee the operational continuity of hydroelectric power plants throughout the year based on weather characteristics and components of the catchment area system. This is expected to be established on the concept of the hydrological cycle, which shows that some of the rainwater that falls on the earth's surface forms as overland flow. Meanwhile, some seep underground while some seep deeper into the ground to form the base flow. The underground water rises to form an underground flow and comes out as springs in the river flow when there is no rainfall (Rasmy et al., 2019). It is important to note that the inputs into the hydrological cycle are continuously the same as the output because it is a closed system and this is known as water balance (Pamela et al., 2015). Moreover, a river is formed based on the combination of the runoff from groundwater flow and the rain that falls directly into its water body.

Mishra (2013) examined watershed modelling with Curve Number $(\mathrm{CN})$ parameters focusing on the rain data for 10 years, and the results showed the river discharge throughout the period in different weather conditions. The study is considered very important and has been used over the years by hydrologists and engineers to determine suitable locations for hydroelectric power plants. Derdour et al. (2013) also used HEC-HMS modelling to predict the surface runoff at the semi-arid region of Ain Sefra watershed in southwestern Algeria while the hydrologic losses and effective rainfall transformation were determined using the SCS curve number and SCS unit hydrograph method, respectively. The results were accepted to be used in stimulating rainfall-runoff. Moreover, Ningaraju et al. (2016) showed the possibility of effectively integrating the Soil Conservation Services Curve Number (SCS-CN) method with GIS to estimate runoff at the 
Kharadya mill watershed in India. The method also can improve land use planning and watershed management.

These previous studies showed the importance of the SCS Curve Number hydrological modelling technique with hydrograph unit for hydrologists in using rivers for power generation, irrigation, drinking water supply, and other water resources needs. This is considered necessary due to the need for the data on river water volume or discharge over time to ensure proper and sustainable operation.

This present study also used a hydrological modelling technique with SCS-CN hydrological model to identify the watershed parameters using the rain data from a station installed in the watershed area as the input. Moreover, HECHMS software analysis was used to generate the hydrograph and time series output data, while the river discharge value used for power generation energy was analyzed using the flow duration curve (FDC) method. The dependable discharge value and estimated height of falling river water were used to obtain the value of possible electrical energy generated by the Taludaa-Gorontalo River flow through the use of the electrical power equation. Therefore, this study was conducted to model river flow energy using hydrological modelling techniques to obtain the spatiotemporal river discharge characteristics needed to ensure the sustainability of hydroelectric power plant operations throughout the year.

\section{Methods}

\section{Research method and data}

This research was conducted using a field survey and hydrological modelling analysis. The hydrological modelling analysis was used to determine the value of river discharge for energy power generation, while the field survey was applied to determine the actual conditions of the watershed. Moreover, the rainfall data used as the main input to HECHMS were obtained through the automatic rainfall recorder (ARR), the rain station data logger installed in the TaludaaGorontalo watershed. Meanwhile, the water level data were retrieved from data loggers at the automatic water level recorder (AWLR) station installed at the observation point of the Taludaa River discharge. The condition of the watershed parameters includes the area, curve number, which represents land use and soil type, time lag which is the delay between the maximum rainfall amount and the peak discharge; and the initial abstraction, which is the parameter that accounts for all losses before runoff were analyzed with ArcGIS software. A topographic map on a scale of 1:25,000 obtained from the Indonesian Geospatial Information Agency for the year 2019 was used to generate secondary data for these parameters. The data from the Spot Satellite Imagery 6 and 7 from LAPAN Republik Indonesia for 2018 were also used.

\section{Hydrological modelling}

Hydrological modelling simplifies complex elements and components to make people understand the earth's hydrological phenomena. The models serve as a simple description of the actual hydrological system and are created to investigate the function and response of water catchment areas to several inputs. They can be used to investigate and apply the findings in predicting future hydrological events $s_{2}$ describe the rain falling in the catchment area of a watershed and its subsequent processing in the system, also produce hydrograph output from river flow rates.
SCS-CN modelling technique used in this study is to analyze the occurrence of river flow discharge as a function of effective rainfall in catchment areas, land cover, land use, and soil antecedent moisture (Andrzej et al., 2020). In this model, the land use function, soil type, and initial moisture were represented by the curve number $(\mathrm{CN})$ parameter determined by considering the antecedent moisture condition (AMC), an index of basin wetness. Meanwhile, it is possible to determine the AMC value based on the rain that falls before the $\mathrm{CN}$ calculation (Silveira et al., 2000).

The CN value of a watershed can be estimated using the SCS table and soil hydrology classification. It can also be calculated as a $\mathrm{CN}$ composite for watersheds with different soil types and land usage using Equation (1).

$$
C N=\frac{\sum A_{i}\left(C N_{i}\right)}{\sum A_{i}}
$$

where $\mathrm{CN}$ is the total composite value of the runoff volume calculated by HEC-HMS, iis the land usage index and soil type, $\mathrm{CN}_{\mathrm{i}}$ is the $\mathrm{CN}$ value of the distribution of the watershed, and $\mathrm{A}_{\mathrm{i}}$ is the area of the watershed.

\section{HEC-HMS hydrological model}

The hydrological model (HEC-HMS) was designed to simulate runoff based on the rainfall input in a watershed and the application of certain sub-watershed components such as the sub-basin, loss, transform, and baseflow as inputs. The method used to determine the loss in this study was the SCS-CN, the transform was evaluated using the SCS unit hydrograph, and the base flow was based on the recession.

The volume of water infiltrated into the soil was calculated using the following Equation (2).

$$
S=25.4\left(\frac{1000}{C N-10}\right)
$$

where $S$ is the water infiltrated into the soil $(\mathrm{mm})$. The relationship between $S$ and the initial linear abstraction $\left(I_{a}\right)$ was further explained using Equation (3).

$$
I_{a}=0.2 S
$$

Time lag (TL) is the time difference between the peak of rain and the peak of the hydrograph, which is normally analyzed using $\mathrm{TL}=0.6 \mathrm{~T}_{\mathrm{c}}$ where $\mathrm{T}_{\mathrm{c}}$ is the concentration-time required by water to move from the farthest place (upstream of the subwatershed) to the observation point of water flow (outlet). It is normally calculated using the Kirpich equation as follows.

$$
T_{c}=0.01947\left(L^{0.77} S^{0.385}\right)
$$

where $L$ is the length of the main river basin, $s$ is the slope of the watershed $\left({ }^{\Delta H / L)}\right.$, and ${ }^{\Delta H}$ is the difference between the upstream and outlet heights. Therefore, the main components needed as inputs for the sub-basic parameters in HEC-HMS are presented in Table 1.

Table 1. Components of sub-DAS parameters used as input for the HEC-HMS

\begin{tabular}{cl}
\hline Component & \multicolumn{1}{c}{ Parameter } \\
\hline Sub Basin & Area $\left(\mathrm{km}^{2}\right)$ \\
& Initial abstraction $(\mathrm{mm})$ \\
Loss & Curve Number \\
& Impervious $(\%)$ \\
Transform & Time Lag (min) \\
& Initial discharge $\left(\mathrm{m}^{3} / \mathrm{s}\right)$ \\
Base Flow & Recession constant \\
& Flow $\left(\mathrm{m}^{3} / \mathrm{s}\right)$
\end{tabular}


The hourly rainfall data obtained from rain stations (ARR) installed in the watershed area at a certain time (forming 1 hydrograph curve) were used as the input in the time series data manager. Moreover, the HEC-HMS simulation process conducted with the watershed parameter components and rain data were used to obtain the hydrograph output and river discharge values at a certain time (only forming 1 discharge hydrograph curve). However, a model calibration process was required because the results produced in the simulation did not match the real-life measurements.

\section{Model calibration process}

The model calibration process is needed to test the results produced from the simulation, which is the hydrograph output, to ensure it is in accordance with the actual river discharge from the observation point. This was conducted in the HEC-HMS through the optimization trial manager process, which involved obtaining field river discharge through direct observation or measurement with the focus on the minimum and maximum water levels at a particular time. It is also important to note that all the values recorded were adjusted to the water level value on the staff gauge.

The discharge data observed were recorded in relation to the time and date of measurement and later paired with the river stage data recorded using the AWLR logger installed in the river flow at the observation site. The application of the discharge rating curve method for the pairing led to a curved line equation $(\mathrm{Y}=\mathrm{XZ})$ which was further used to determine the $\mathrm{Y}$ value or debit series value by entering all the water level values in variable $\mathrm{X}$ as indicated in Figure 1.

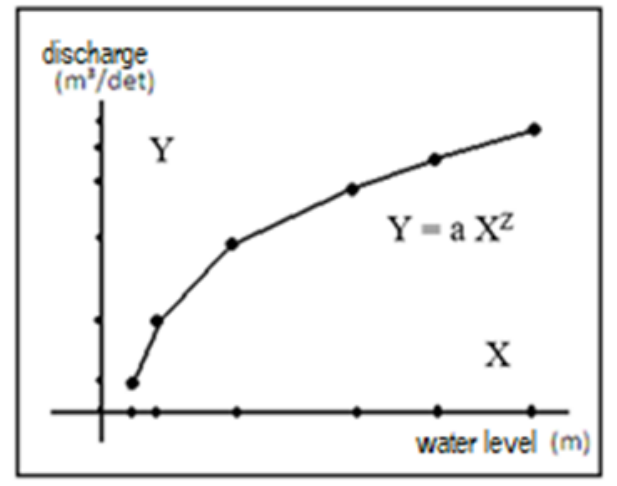

Figure 1. The curve of water level versus discharge

This rating curve can be used to determine the river discharge time-series data for a certain period. When the hydrograph produced is different from the value measured up to $85 \%$, there is a need to conduct an optimization calibration process by changing the value of the sub-watershed components, including the $\mathrm{CN}$, TL, and Ia, from the minimum to the maximum value. A model hydrograph that resembles the one from the observations is expected to be obtained after several optimizations, and this means the model is acceptable to be used in determining the river flow rates. Moreover, it is also possible to use the changed parameters to simulate the discharge using the time-series rain data as the input in the HEC-HMS to produce the time-series river discharge data required to be used as river discharge value over time (temporal ratio).

\section{Dependable discharge analysis}

The river discharge used for power generation needs to meet reliability standards by continuously being within the determined threshold. For example, the dependable discharge needed for electric power generation is $85 \%-90 \%$, and this means the discharge rate for the overall time-series river flow events needs to be within this range to be eligible for use in electricity generation. The dependable discharge, which is based on the frequency of events, was analyzed in this study using the flow duration curve (FDC) method based on the formula in Equation (5) (Lei Ye et al., 2015).

$$
A=\frac{(n-q)}{n} 100 \%
$$

where $\mathrm{n}$ is the number of observations and $\mathrm{q}$ is the number of failures with a specific focus on the situation when the recorded discharges are smaller than the dependable discharge. The FDC curve involves sorting the discharge data from the largest to the smallest on the $\mathrm{Y}$-axis and creating a probability ranking of the number of events from $1 \%-100 \%$ on the $\mathrm{X}$-axis. This led to the calculation of the probability of discharge for each percentage using Equation (6).

$$
P=100[M /(n+1)]
$$

where $\mathrm{P}$ is the probability of water discharge, $\mathrm{M}$ is the ranking position of debit data, and $\mathrm{n}$ is the total data.

The minimum dependable discharge to turn the electric generator turbine was $90 \%$ of the total available flow rate (time series) as determined based on the height of the hydrograph presented in Figure 2.

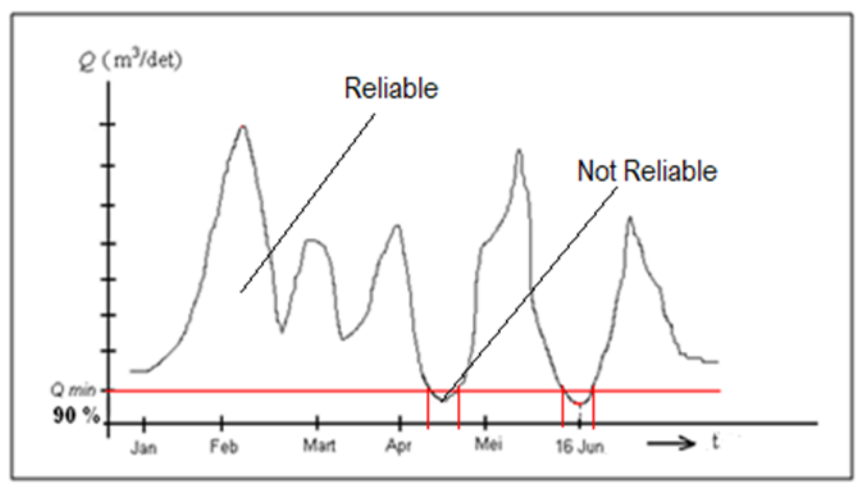

Figure 2. Determination of $90 \%$ main discharge

\section{Head Analysis}

The waterfall height design determines the energy available to move the turbine in a proposed power plant. This is the reason the power plant is normally constructed based on the analysis of the slope in the watershed area such that a high slope is required to obtain the sufficient water flow needed to turn the turbine. Moreover, the location for the power plant should not be too far from the water discharge measurement point, while an appropriate water channel needs to be constructed to produce the optimal volume of river flow needed to turn the power generator turbine. It is important to note that the water drop height or head value is usually determined by subtracting the height of the observation point from the height of the hydropower building point. It can also be calculated by adding the location height with the river height after it has been dammed. Therefore, the determination of the head based on the assumed ideal field distance is presented in Figure 3.

Analysis of water energy for hydroelectric power generation

Hydroelectric power generation converts energy from hydropower at a certain height and discharges to electricity 

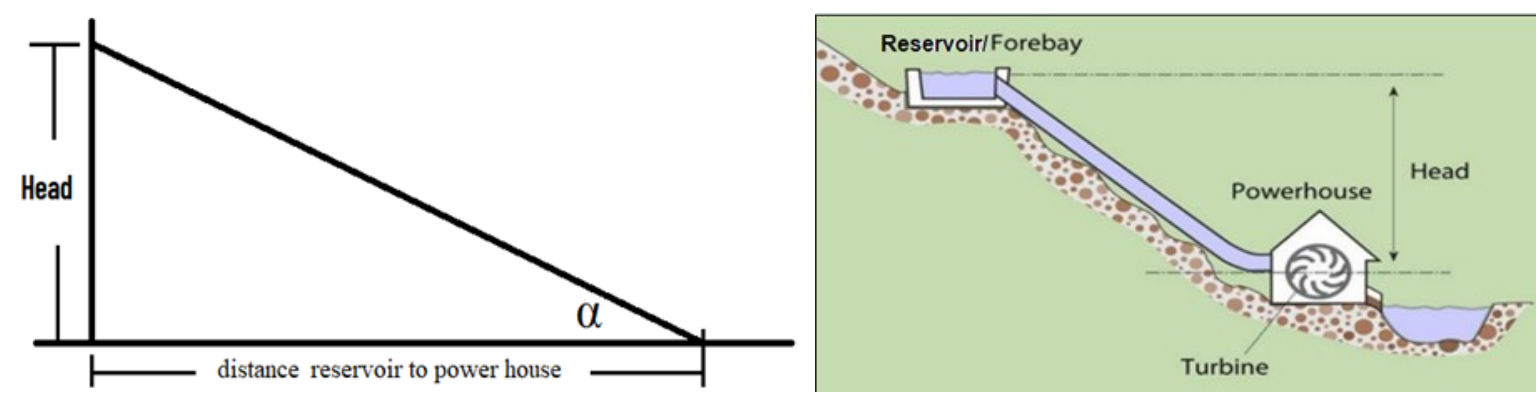

Figure 3. Determination of the head based on distance from the reservoir to the powerhouse

using water turbines and generators. It is possible to calculate the power generated by considering the efficiency of the hydroelectric power, which is usually set at $75 \%$. The value of the electric power generated by hydropower in a river was calculated using the following Equation (7) (Bertrand et al., 2018).

$$
P=9.81 Q H \eta_{e}
$$

where $P$ is the theoretical power output $(\mathrm{kW}), H$ is the effective waterfall $(\mathrm{m}), Q$ is the water discharge $\left(\mathrm{m}^{3} / \mathrm{s}\right)$, and $\eta_{e}$ is the efficiency of the hydropower generator.

\section{Results and Discussion}

\section{Condition of the Taludaa-Gorontalo watershed}

This study was conducted at the Taludaa-Gorontalo watershed with the application of ArcGIS 10.5 to process the data from its topographic map with a scale of 1:250.000 (2019) as well as the data from Spot Images 6 and 7 ( 2018) as shown in Figure 4. The watershed area was found to be 8460.03 hectares or 84.60 $\mathrm{km}^{2}$, and the length of the main river was recorded to be 31.21 $\mathrm{km}$. Moreover, the topography of the watershed is a plateau with a slope of more than $30 \%-45 \%$. The soil has a rough texture, and the vegetation cover is dominated by high-density vegetation covering $81.97 \%$ of the area. The land use is mainly for the forest with $53.27 \%$ followed by dry agricultural land with $18.56 \%$, residentials with $15.07 \%$, and others with $13.20 \%$, and this has a significant effect on the characteristics of the river discharge hydrograph, specifically at the peak of the surface runoff.

\section{Watershed Parameter}

The analysis of the soil maps showed there are three types of soils in the watershed, and these include the Alfisol, Inceptisol, and Mollisol, which are classified as muddy clay and loamy sand according to the soil texture classification of USDA. Moreover, the

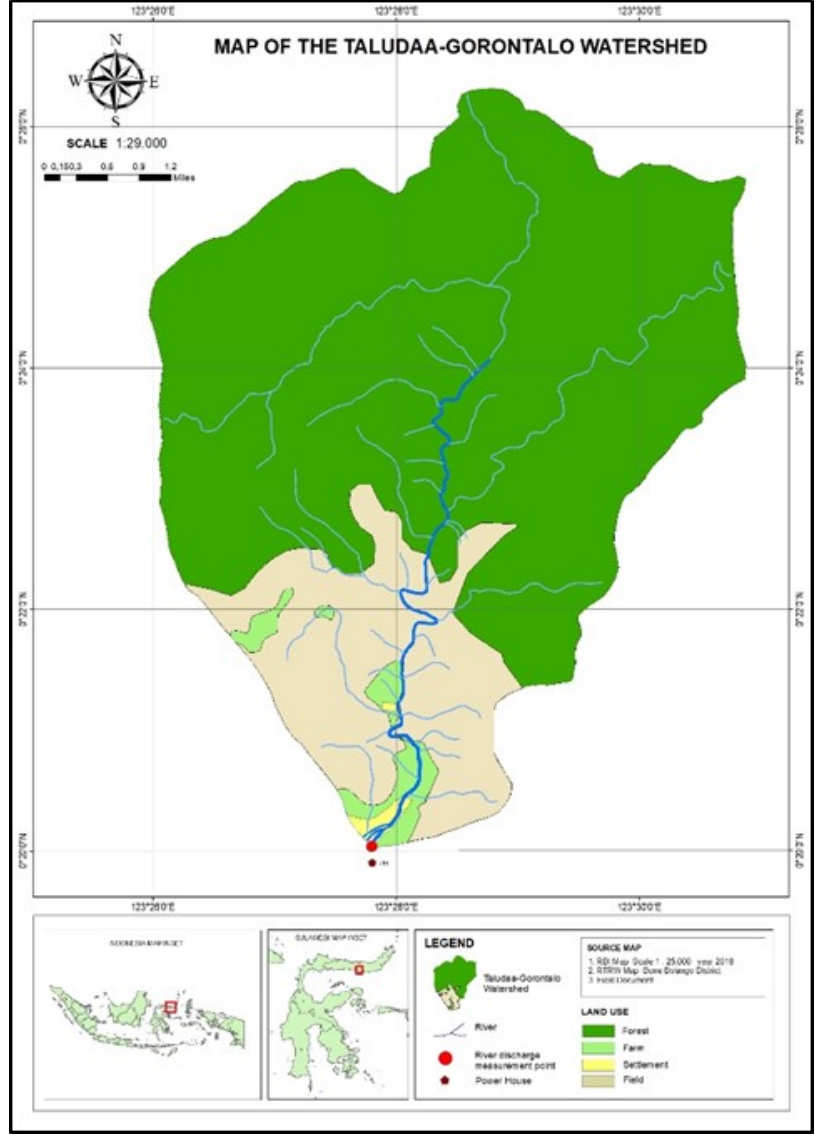

Figure 4. Map of the Taludaa-Gorontalo watershed

$\mathrm{CN}$ value of the watershed area was calculated based on land use, land cover, and soil hydrology group, as presented in Table 2. Meanwhile, the sub-watershed components used for the SCS-CN model analysis were sub-basin, loss, transform, and baseflow using the values presented in Table 3 .

Table 2. Taludaa-Gorontalo watershed $\mathrm{CN}$ analysis

\begin{tabular}{|c|c|c|c|c|c|c|}
\hline Land-use type & Condition & $\begin{array}{c}\text { Density } \\
(\%)\end{array}$ & $\begin{array}{c}\text { spacious } \\
\left(\mathrm{km}^{2}\right)\end{array}$ & $\begin{array}{l}\text { Soil hydrol- } \\
\text { ogy }\end{array}$ & $\mathrm{CN}$ & $\begin{array}{c}\text { CN composite }= \\
4 \times 6\end{array}$ \\
\hline Settlement & $\begin{array}{c}\text { 70\% imperme- } \\
\text { able }\end{array}$ & $30 \%$ & 3.46 & $\mathrm{C}$ & 70 & 242.20 \\
\hline Forest & Ugly & $50 \%$ & 12.24 & $\mathrm{C}$ & 69 & 844.56 \\
\hline Agricultural farming & Ugly & $<25 \%$ & 4.26 & $\mathrm{C}$ & 75 & 319.50 \\
\hline other areas of use & Medium & $30-70 \%$ & 3.03 & B & 60 & 181.80 \\
\hline \multicolumn{6}{|c|}{22.99} & 1588.06 \\
\hline \multicolumn{7}{|c|}{$\mathrm{CN}$ composite $=1588.06 / 22.99=69.076$} \\
\hline
\end{tabular}


Table 3. Taludaa watershed morphometry component analysis

\begin{tabular}{ll}
\hline \multicolumn{1}{c}{$\begin{array}{c}\text { Parameters of the watershed } \\
\text { morphometry }\end{array}$} & \multicolumn{1}{c}{ Value } \\
\hline Centre of gravity & $\mathrm{X}=533,258,7636$ \\
& $\mathrm{Y}=51,252,9415$ \\
Gradient & $18.3 \%$ \\
Length of the main river & $9.996 \mathrm{~km}$ \\
Slope & 0.065 \\
The river segment height & Upstream $=850(\mathrm{~m})$ \\
& outlet $=100(\mathrm{~m})$ \\
\hline
\end{tabular}

(Source: Analysis result using GIS, 2020)

Rainfall data, observed discharge, and watershed parameters

The discharge data and water level data were plotted on a scattered plot using Microsoft Excel to produce the curve equation $\left(Y=a X^{2}\right)$ as shown in Figure 5. The curve flow diagram produced $\mathrm{Y}=18.84 \mathrm{X}^{2,24}$ with $\mathrm{R}^{2}=0.996$, while the river flow discharge value was obtained by entering the water level value as indicated in Table 4. Moreover, the curve flow equation with the river stage data pair (X variable) and measurement discharge ( $\mathrm{Y}$ variable) was used to determine the river flow time-series value, which is the discharge data on August 03 and 04, 12:00-16:00, which subsequently used for the control specification required in HEC-HMS. Meanwhile, the data for the Taludaa sub-watershed components were processed and calculated using ArcGis, as presented in Table 5.

Table 4. Water level pair data and observation discharge in the Taludaa River

\begin{tabular}{ccc}
\hline Date, Year & $\begin{array}{c}\text { Level Water } \\
(\mathrm{m})\end{array}$ & $\begin{array}{c}\text { Discharge }\left(\mathrm{m}^{3} /\right. \\
\mathrm{s})\end{array}$ \\
\hline $09 / 06-2020,16.35$ & 0.40 & 2.30 \\
28/06-2020, 16.53 & 0.41 & 2.31 \\
30/06-2020, 17.15 & 0.41 & 2.31 \\
01/07-2020, 17.00 & 0.39 & 2.29 \\
22/07-2020, 15.00 & 0.40 & 2.31 \\
24/07-2020, 16.00 & 0.53 & 4.08 \\
$05 / 08-2020,09.00$ & 0.61 & 6.51 \\
$17 / 08-2020,14.00$ & 0.89 & 13.50 \\
20/08-2020, 17.00 & 1.11 & 24.63 \\
\hline
\end{tabular}

(Source: Measurement results, 2020)

Table 5. Taludaa watershed components

\begin{tabular}{llc}
\hline \multicolumn{1}{c}{ Component } & Sub-watershed parameter & Value \\
\hline Sub Basin & Area $\left(\mathrm{km}^{2}\right)$ & 22.99 \\
Loss & Initial abstraction (mm) & 15.23 \\
SCS Curve Number & Curve Number (AMC II) & 69.08 \\
& Impervious area (\%) & 2.30 \\
Transform & & \\
SCS Unit & Time Lag (min) & 83.00 \\
Hydrograph & & \\
& Initial discharge $\left(\mathrm{M}^{3} / \mathrm{s}\right)$ & 3.30 \\
Baseflow & Recession constant & 0.35 \\
& Flow $\left(\mathrm{m}^{3} / \mathrm{s}\right)$ & 4.40 \\
\hline
\end{tabular}

(Source: Analysis result, 2020)

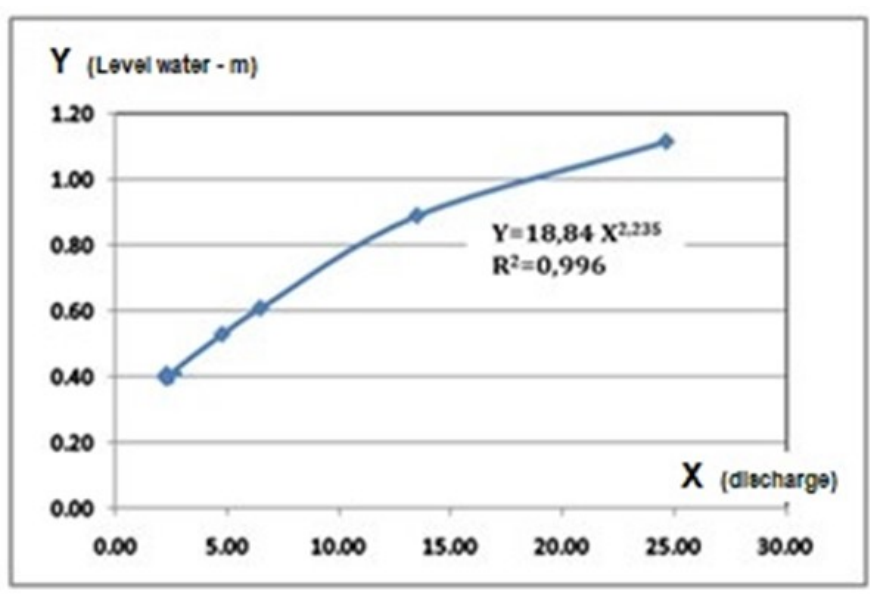

Figure 5. Curve flow diagram to obtain the value of the equation $\mathrm{Y}=\mathrm{aX}$

\section{Model analysis with HEC-HMS}

The HEC-HMS process was conducted by filling the values in Table 5 for the components, including the basin model, meteorological basin, control specification, time-series data, and paired data managers. Meanwhile, the simulation results obtained based on the rain data, simulated discharge model, and observed discharge on the $3^{\text {rd }}$ of August 2020, 04:00-16:00, are presented in Figures 6 and 7.

Figure 7 shows that the Taludaa River discharge modelling results indicate a difference between the discharge values obtained from the model and observation in relation to both the volume and peak. Therefore, calibrations were conducted in the optimization trial aspect of the HEC-HMS by adjusting the values of the sub-basin components, including the CN, Ia, TL, and Rc, from the minimum to the maximum to modify the model discharge hydrograph.

Several optimizations were conducted on the sub-watershed component values, as shown in Figure 8.

The optimization process results are shown in Figure 8, with the model discharge hydrograph graph found to resemble the observed discharge hydrograph at point E. This means the hydrological model is accepted to be used in determining the discharge value for the Taludaa River, with the difference in flow volume recorded to be $44.76 \mathrm{~mm}$ and the peak flow was $60.5 \mathrm{~m}^{3} / \mathrm{s}$. Moreover, the changes made to the values of the parameters were 15.23 for the initial abstraction (Ia), 84 for the time lag (TL), 66 for the curve number $(\mathrm{CN}), 3.3$ for the initial discharge (Id), and 0.07 for the recession constant (Rc).

The overall river discharge value (spatiotemporal) was obtained through a simulation conducted using these optimized parameter values, and rainfall data between June and September 2020 and the results are presented in Figure 9.

This HEC-HMS hydrologic modelling was also applied to predict the surface runoff of Ain Sefra watershed in southwestern Algeria, while the SCS curve number loss method was used to determine the hydrologic losses, and the SCS unit hydrograph method was employed for the effective rainfall transformation to provide very satisfying results (Derdour et al., 2018).

Determination of the dependable discharge of the Taludaa River in Gorontalo

The dependable discharge analysis conducted using the FDC method based on the model's time-series river discharge value showed that the mainstay river discharge value was $10.1 \mathrm{~m}^{3} / \mathrm{s}$, as indicated in Figure 10. 


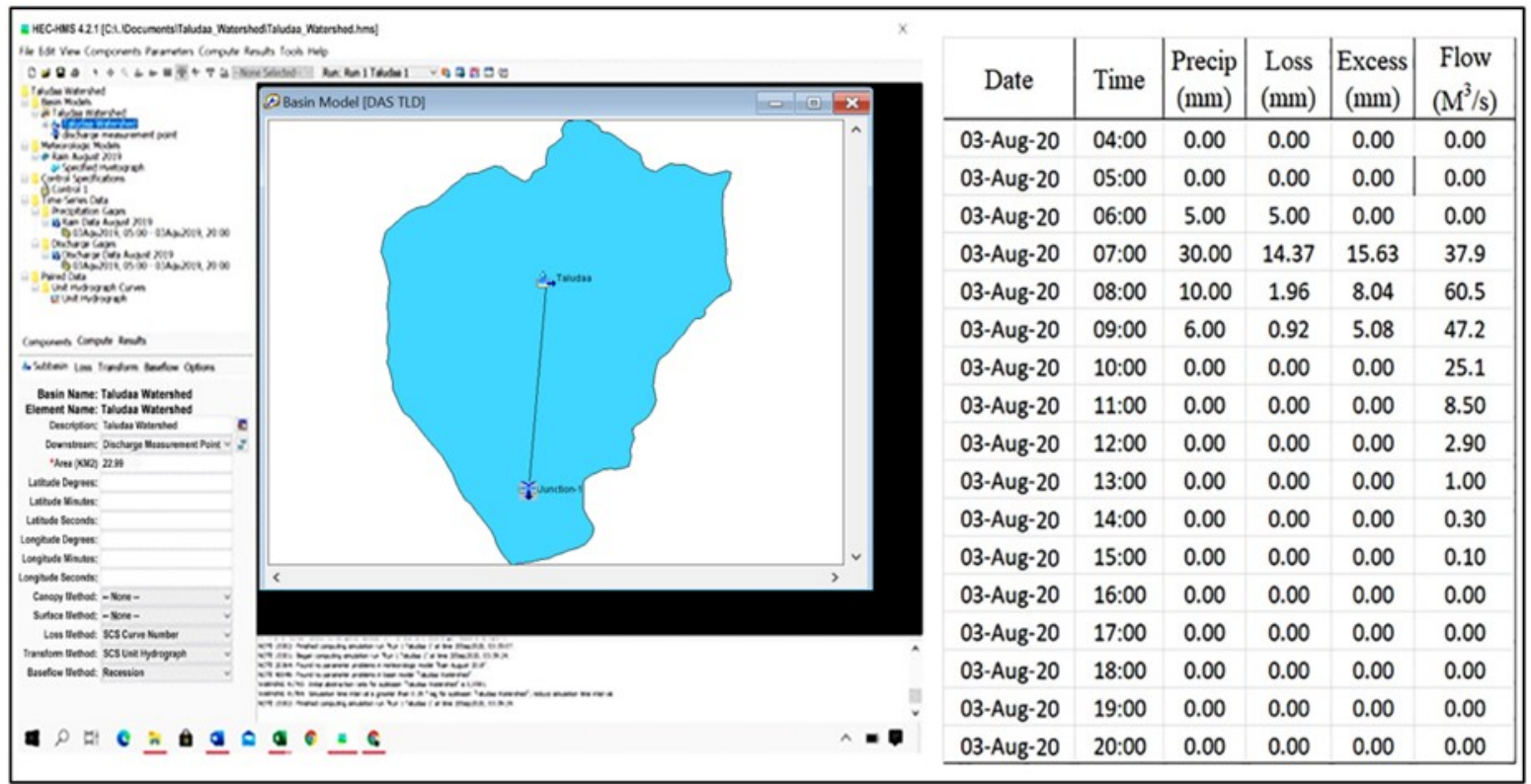

Figure 6. HEC-HMS model process for determining river discharge

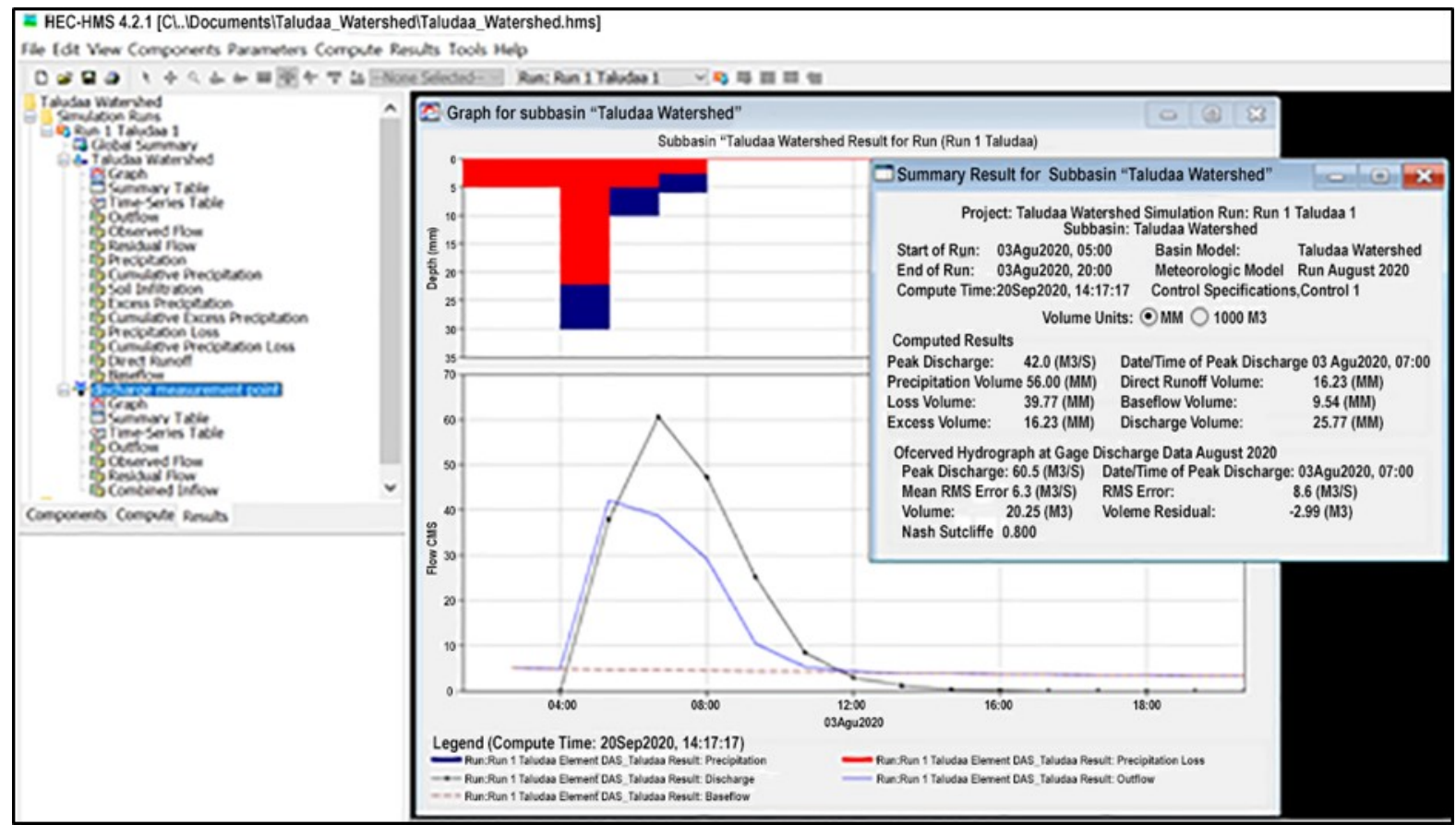

Figure 7. The results of modelled rain into discharge using HEC-HMS

Electric power generation potential

The electric resource potential in the Taludaa River was estimated by measuring the value of the mainstay discharge, head value, and efficiency of the power plant. The height of the river's fall determined based on the morphometric conditions of the river was $3.25 \mathrm{~m}$, and this means the construction of the dam with a height of $5 \mathrm{~m}$ will make the head become $8.25 \mathrm{~m}$. Moreover, the estimated power plant efficiency was estimated at $75 \%$, and this means the electrical energy to be obtained from the Taludaa River is:

$$
\mathrm{P}=9.8 \times 10.1 \times 8.25 \times 75 \%=612.438 \mathrm{~kW} .
$$

Microscale hydroelectric power plants can be constructed parallel using the wastewater from generator 1 for generator 2 and others to obtain additional power. The output power of these added plants can also be increased by raising the value of the water drop height (head) because a higher water drop usually leads to a greater electrical power to be generated by a hydroelectric power plant.

\section{Conclusion}

The river flow rates in the Taludaa-Gorontalo watershed were analyzed by transforming rain into streams using the SCS-CN model. The watershed parameters used as the inputs for the HEC-HMS hydrological model include the maximum water retention potential (as the initial abstraction value [Ia] or water loss before runoff), which was 18 , the time between peak rainfall and peak discharge (determined by TL) which was $60 \mathrm{~min}$, the $\mathrm{CN}$ used to represent the conditions of land use in the area set at 40.63, and the soil hydrology, Rc, which was 0.07 . Moreover, the temporal ratio of the river's dependable discharge was found to be $10.1 \mathrm{~m}^{3} / \mathrm{s}$ using the FDC method, while the potential water drop height of the 


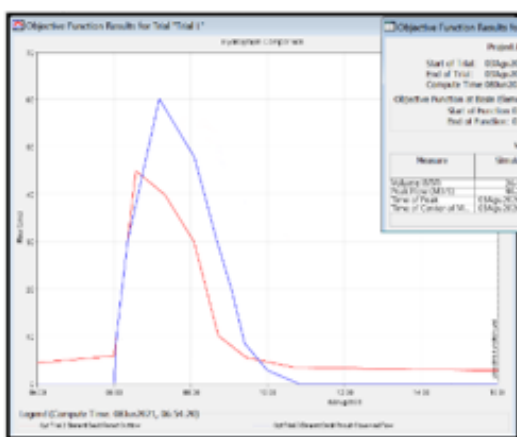

A

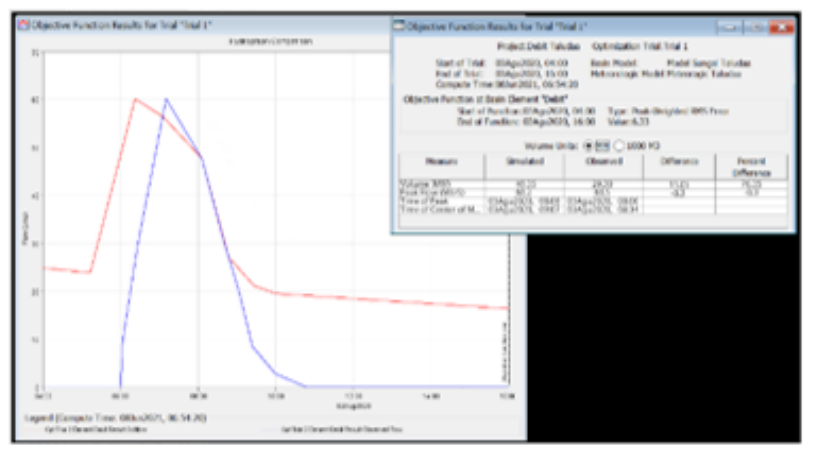

C

D
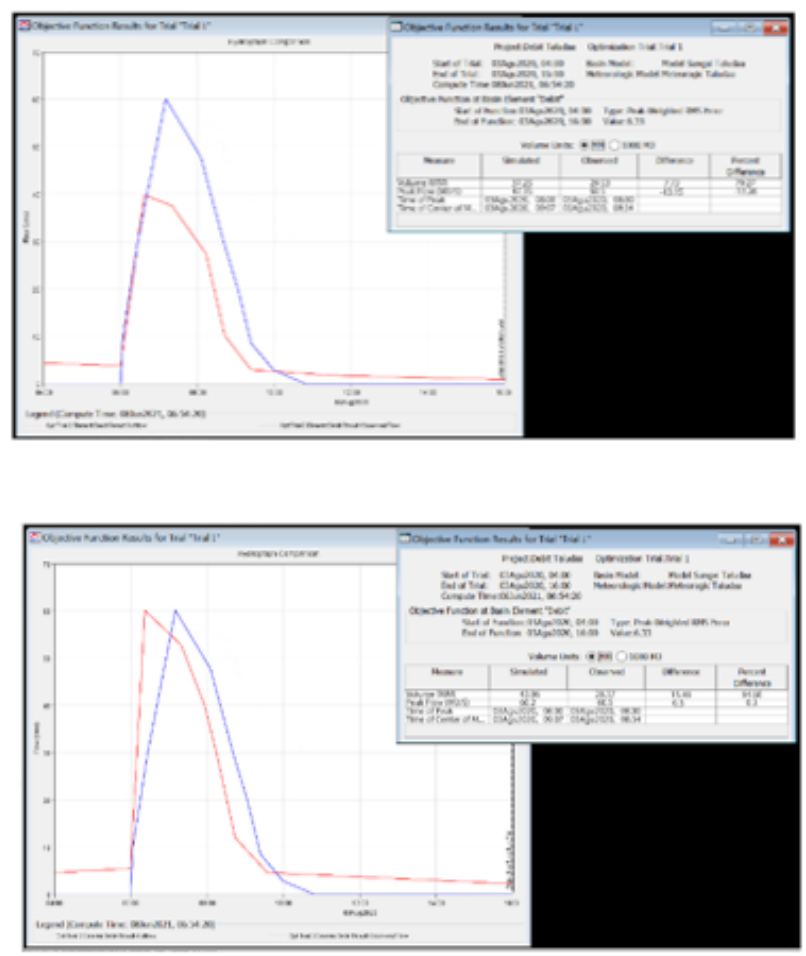

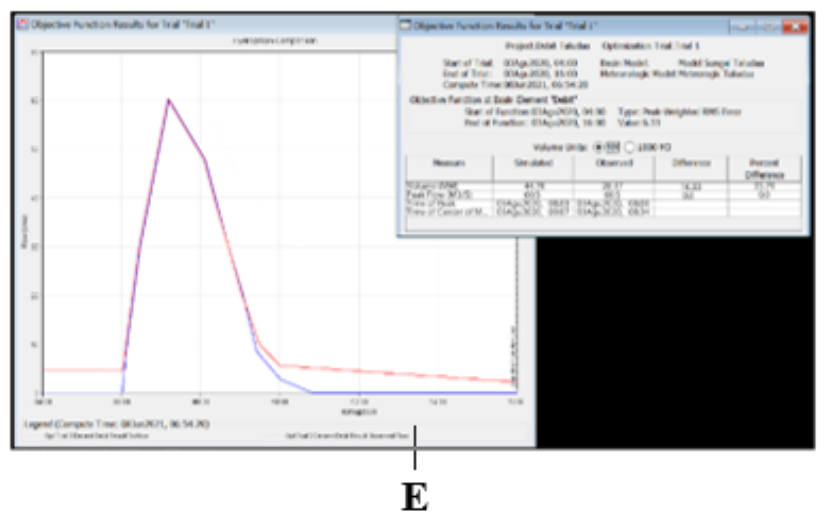

Figure 8. Result of the HEC-HMS optimization process after several changes in sub-watershed components

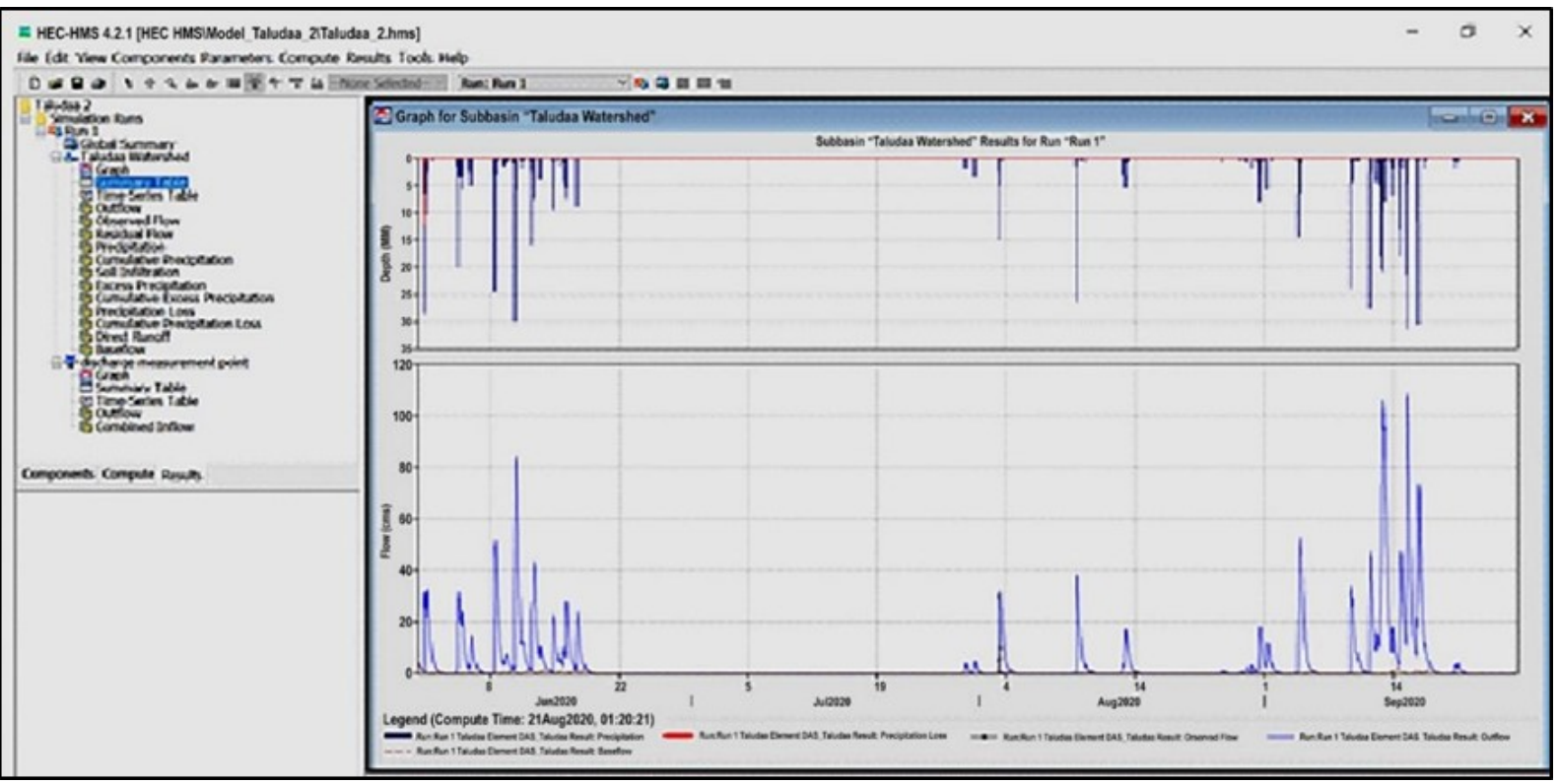

Figure 9. Taludaa River discharge hydrograph between June and September 2020 and the result of the HEC-HMS process 


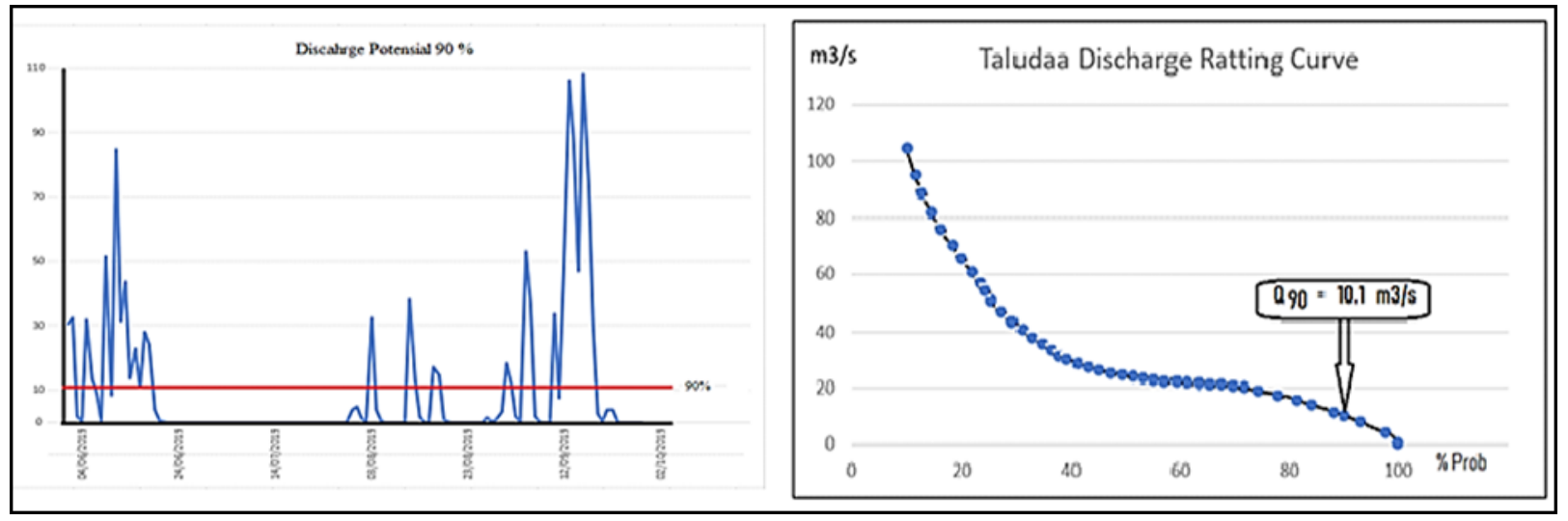

Figure 10. Determination of the river's dependable discharge using the FDC method

river after damming was found to be $8.25 \mathrm{~m}$, and the power plant efficiency was assumed to be $75 \%$. These values were used to calculate the potential electric power in the Taludaa River to be $612.438 \mathrm{~kW}$. This means it is possible to continuously generate power when there is no rainfall at certain times in the catchment area by relying on the Taludaa -Gorontalo River flow energy to generate the power as indicated by the 2020 analysis.

\section{References}

Amos T., Kabo-Bah, Chuks. J, Nokoe K, Mulugetta Y, Obeng-Ofori $\mathrm{D}$, and Akpoti $\mathrm{K}$, "Multiyear rainfall and temperature trends in the Volta river basin and their potential impact on hydropower generation in Ghana," Climate, vol. 4, no. 4, p. 49, 2016.

Andrzej W., Devendra M.A, Peter C., Mariond S.P., Assessment of storm direct runoff and peak flow rates using improved SCS-CN models for selected forested watersheds in the Southeastern United States, Journal of Hydrology: Regional Studies Volume 27, February 2020,

Derdour A, Bouanani A, Babahamed K, 2018, Modelling rainfall runoff relations using HEC-HMS in a semi-arid region: Case study in Ain Sefra watershed, Ksour Mountains (SW Algeria), Journal Of Water And Land Development, No. 36 (I-III): 4555.

Lei Ye,Wei Ding, Xiaofan Zeng, Zhuohang Xin, Jian Wu and Chi Zhang, Inherent Relationship between Flow Duration Curves at Different Time Scales: A Perspective on Monthly Flow Data Utilization in Daily Flow Duration Curve Estimation, Journal MDPI Water Vol. 10, Issue 8, July 2018.

Mishra S.K, Gajbhiye S, Pandey A, September 2013, Estimation of design runoff curve numbers for Narmada watersheds (India), Journal of Applied Water Engineering and Research Vol. 1, No. 1, 69-79, 2013.

Ningaraju H.J, Ganesh Kumar S, Surendra H J, May 2016, Estimation of Runoff Using SCS-CN and GIS method in ungauged watershed: A case study of Kharadya mill watershed, India. International Journal of Advanced Engineering Research and Science (IJAERS) Vol-3, Issue-5, May- 2016.

Pamela J. Edwards, Karl W.J. Williard, Jon E. Schoonover, Fundamentals of Watershed Hydrology, Journal of Contemporary Water Research \& Education Volume 154, Issuel April 2015.

Rasmy M, Sayama T, and Koike T, "Development of water and energy Budget-based Rainfall-Runoff-Inundation model (WEBRRI) and its verification in the Kalu and Mundeni River Basins, Sri Lanka," J. Hydrol., vol. 579, p. 124163, 2019.

Samora I, Manso P, Franca M.J, Schleiss A.J, and Ramos H.M, "Opportunity and economic feasibility of inline microhydropower units in water supply networks," J. Water Resour. Plan. Manag., vol. 142, no. 11, p. 4016052, 2016.

Silveira L, F. Charbonnier, J.L. Genta, The antecedent soil moisture condition of the curve number procedure, Hydrological Sciences-Journal des Sciences Hydrologiques, 45(i) February 2000.

Tsai Y.C, Chiu C.P, Ko F.K, Chen T.C, and Yang J.T, "Desalination plants and renewables combined to solve power and water issues," Energy, vol. 113, pp. 1018-1030, 2016. 